\title{
Semantic Play and Possibility
}

\section{Section Introduction}

The ironist ... takes the unit of persuasion to be a vocabulary rather than a proposition. Her method is redescription rather than inference. Ironists specialize in redescribing ranges of objects or events in partially neologistic jargon, in the hopes that by the time she is finished using old words in new senses, not to mention introducing brand new words, people will no longer ask question phrased in the old words. (Rorty, 1989, p. 78)

Unlike the analytic science of the Enlightenment, complexity science defines itself more in terms of its objects of study than its modes of inquiry. This aspect of complexity thinking arises in the realization that certain sorts of self-organizing, self-maintaining phenomena give rise to new rules and transcendent possibilities. They cannot be reduced to simpler elements, but must be studied at the levels of their emergence. In domains such as educational research, where analytic sensibilities have been overwhelmingly dominant for most of their histories, complexity thinking thus engenders a need to interrogate common sense definitions of core vocabularies. Following Rorty (above), there is a need to redescribe, using old words in new ways and inventing new terms. The purpose of this section of Complicity is to take up Rorty's challenge. Contributors to this section are asked to select one term that is prominent in the educational literature and to give it a complexivist spin.

In this issue we have four semantic plays. Heesoon Bai addresses the issue of ethics in education from a complex Zen perspective, Bernard Ricca plays with enframing, Walter Gershon takes on validity and finally, Sarah Smitherman Pratt plays with the notion of bifurcations. The contributions to this section are invited. If you would like to submit an entry, or to suggest an educational thinker and/or educational term that might be included in subsequent issues, please contact the editors.

Reference

Rorty, Richard (1989). Contingency, irony, and solidarity. New York: Cambridge University Press.

Complicity: An International Journal of Complexity and Education

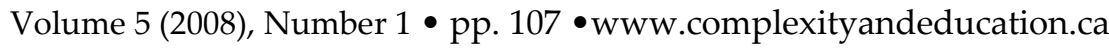

